\title{
Marine Aerosol-Cloud-Climate Interaction
}

\author{
Nicholas Meskhidze, ${ }^{1}$ Charles R. McClain, ${ }^{2}$ Markus D. Petters, ${ }^{1}$ Elisabetta Vignati, ${ }^{3}$ \\ Olaf Stetzer, ${ }^{4}$ Chris Osburn, ${ }^{1}$ and David J. Kieber ${ }^{5}$
}

\author{
${ }^{1}$ Department of Marine Earth and Atmospheric Sciences, North Carolina State University, Raleigh, NC, USA \\ ${ }^{2}$ NASA/Goddard Space Flight Center, Greenbelt, MD, USA \\ ${ }^{3}$ Joint Research Centre Institute for Environment and Sustainability Climate Change Unit, Ispra, VA, Italy \\ ${ }^{4}$ Institut $f$. Atmosphäre und Klima, Zürich, Switzerland \\ ${ }^{5}$ Department of Chemistry, State University of New York, College of Environmental Science and Forestry, New York, USA
}

Correspondence should be addressed to Nicholas Meskhidze, nmeskhidze@ncsu.edu

Received 8 December 2010; Accepted 8 December 2010

Copyright (C) 2010 Nicholas Meskhidze et al. This is an open access article distributed under the Creative Commons Attribution License, which permits unrestricted use, distribution, and reproduction in any medium, provided the original work is properly cited.

Concerns over the role of atmospheric aerosols in masking observed climate change have sparked renewed interest in the natural emissions of trace gases (functioning as aerosol precursors) and aerosols. Understanding the aerosol budget in the absence of anthropogenic influence is necessary to establish a baseline aerosol forcing and provide a framework for models to properly interpret the historical climate record. Marine aerosol emissions, their composition, and their effects on clouds and radiation budget remain poorly characterized due to the large areal extent of the oceans and resulting scarcity of observational data. It is therefore not surprising that marine aerosols and associated cloud processes play a major role and present a large uncertainty, in predictions of future climate.

This special issue was motivated by our perceived need to provide a platform for current discussions regarding marine aerosol-cloud-climate interactions. Much research had been performed in the 1950s-1970s following the discovery and initial characterization of the bubble burst process by Woodcock, Blanchard, McIntyre, Duce, and coworkers. A special issue appeared in the Journal of Geophysical Research in 1972 and research continued at a modest level over the next decades. Renewed interest in the subject appeared in the early 2000s, when a number of new studies identified large fractions of organic material in ambient marine aerosol in different locations, sparking an upsurge in laboratory, field, satellite, and modeling studies. These studies aimed to better characterize marine primary and secondary organic aerosol production mechanisms, aerosol mass and number fluxes, size-dependent sea spray enrichment factors, the split between water soluble and insoluble organic fractions, the chemical composition of organic aerosol, as well as to determine the effect of marine organics on cloud microphysical properties. This special issue presents a snapshot of current research topics in this study area. It comprises twelve peerreviewed open access articles spanning the full spectrum of atmospheric science research on this subject.

A number of contributions address the chemical composition of marine aerosols. Rinaldi et al. present a reviews and some innovative results on the chemical composition of primary and secondary marine aerosol, showing seasonal differences in nascent submicron sea spray particle chemical composition collected at the Mace Head Atmospheric Research Station. During low biological activity, submicron marine aerosols were primarily composed of sea salt, while particles collected during high biological activity largely contained nonsea salt sulfate and organics. Rinaldi et al. report distinct seasonal difference even in the organic composition of submicron marine aerosol. During low biological activity soluble and insoluble organic compounds were comparable in abundance, while during high biological activity submicron organics were dominated by water soluble organic matter. Hawkins and Russell use scanning Transmission X-ray Microscopy with Near-Edge X-ray Absorption Fine Structure (STXM-NEXAFS) analysis to classify marine primary organic aerosols collected in the Arctic and southeastern Pacific marine boundary layers into four major chemical types: carboxylic acid-containing 
polysaccharides, low-solubility polysaccharides, calcareous phytoplankton fragments, and proteinaceous particles. Indirect composition measurements are contributed by Wex et al. who report on the hygroscopic behavior of aerosol generated from laboratory bubble-bursting experiments with seawater solutions containing algae exudates. These types of studies provide semiquantitative estimates of the amounts of organics that can be expected from certain processes.

The sea-to-atmosphere exchange of reactive volatile organic compounds (VOCs) and their reaction with oxidants presents a potential source for secondary organic aerosol formation. McVeigh et al. present new data on the turbulent exchange of $\mathrm{O}_{3}$ between open waters and the atmosphere in the absence of phytoplankton blooms. Under these conditions the net exchange rate is generally small, is bidirectional but skewed towards deposition, and deposition rates appear to decrease with increasing wind speed. Coleman et al. use a regional climate model to evaluate dry deposition of ozone over the North East Atlantic and estimate the magnitude of the ozone deposition-driven upward flux of iodine from the ocean. Results of this study show that iodide reactions alone cannot account for observed deposition velocities, suggesting a missing chemical sink due to reactions of ozone with organic matter and chlorophyll at the air-sea interface. In addition to iodine, the ocean is a source for large number of biogenic nonmethane hydrocarbons such as dimethylsulfide (DMS), isoprene, monoterpenes, and derived secondary organic aerosol (SOA) precursors. Shaw et al. present a topical review of about 70 articles on the subject and provide recommendations towards better characterizing and constraining emissions.

A number of studies are devoted to investigating the effect of ocean emissions on aerosol optical depth (AOD) and aerosol-cloud interactions using remotely sensed data. O'Dowd et al. show that sea spray contribution to marine AOD can approach or even exceed values of 0.3 , suggesting that under moderately high wind speed regimes marine emissions can rival those of anthropogenic plumes advecting out into marine environment. By combining data from satellite and field measurement (ground and airborne), Sorooshian and Duong reveal a direct link between ocean emissions and aerosol physiochemical properties during periods of enhanced ocean productivity and low wind speed. However, due to complex cloud microphysical response to aerosol perturbations, the effect of ocean biota on cloud microphysical properties could not be identified with high confidence. To address the difficulties associated with the connection of ocean biological productivity, submicron aerosols, and clouds, Meskhidze and Nenes propose some guidelines for selection of time periods, oceanic regions and statistical methods in remotely-sensed studies. Using the differences in satellite-retrieved total AOD and predicted sea salt AOD at different wavelengths, Meskhidze and Nenesoffer proposed a new approach for exploring causal links between ocean physical and biological systems and abundance of CCN over the oceans.

A number of modeling studies address global and regional sources of marine primary organic aerosol (POA), ocean-derived SOA and potential effects of marine biogenic emissions on a new particle formation and growth over the open ocean. Myriokefalitakis et al. investigate global marine organic aerosol budget using a 3-dimensional chemistrytransport model TM4-ECPL. In this study ocean-derived SOA and submicron POA sources were estimated at about 1.5 $\mathrm{TgC} \mathrm{yr}^{-1}$ and $4 \mathrm{TgCyr}^{-1}$, respectively. Marine submicron POA was considered to be emitted as water insoluble, internally mixed with sea salt aerosols, while the computed marine SOA originated from the DMS $(\sim 78 \%)$, dialkyl amine salts $(\sim 21 \%)$, and marine hydrocarbon oxidation $(\sim 0.1 \%)$. Using regional-scale climate model REMOTE with current emission estimates, Anttila et al. investigated SOA formation over the North East Atlantic during a period of high biological activity. Results of this study show that marine isoprene oxidation makes a negligible contribution to marine organic aerosol budget and cannot explain the observed water soluble organic carbon. Simulations of marine new particle formation and growth by Monahan et al. using the M7 modal aerosol dynamics model indicate that the open ocean new particle production through sulfuric acid $\left(\mathrm{H}_{2} \mathrm{SO}_{4}\right)$-iodine dioxide (OIO) driven nucleation is feasible under coastal and open ocean marine environments. However, only few particles were suggested to reach detectable sizes for $\mathrm{OIO}$ and $\mathrm{H}_{2} \mathrm{SO}_{4}$ alone. Results of Monahan et al. study show that presence of low amounts of organic vapor can have significant impact on marine aerosol number concentrations.

\section{Acknowledgment}

We, the guest editors of this special issue of Advances in Meteorology (AMET), are grateful to all of the authors, reviewers, and AMET stuff. We hope that the papers in this issue will stimulate further development and confidence building for improved characterization of this extremely complex topic.

Nicholas Meskhidze Charles R. McClain Markus D. Petters Elisabetta Vignati Olaf Stetzer Chris Osburn David J. Kieber 

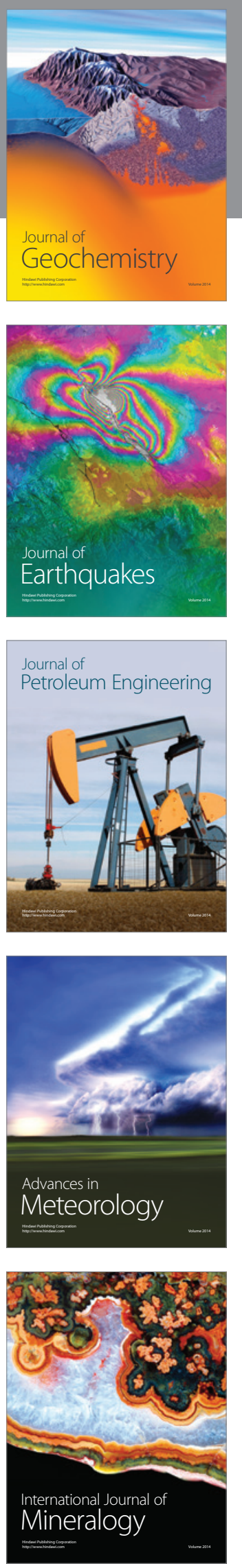
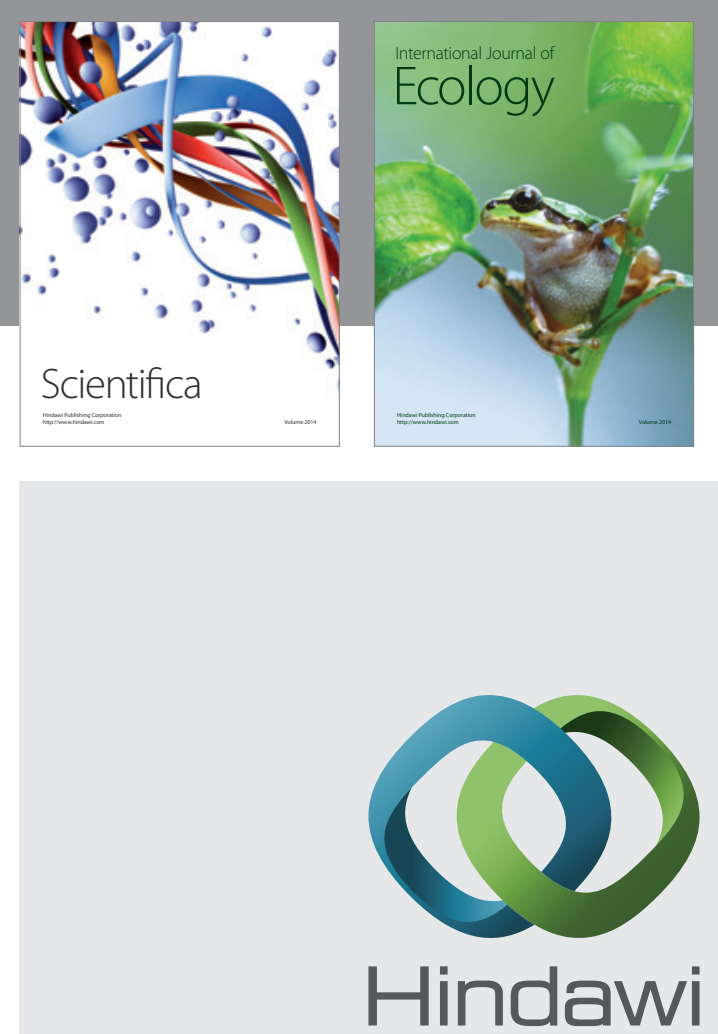

Submit your manuscripts at http://www.hindawi.com
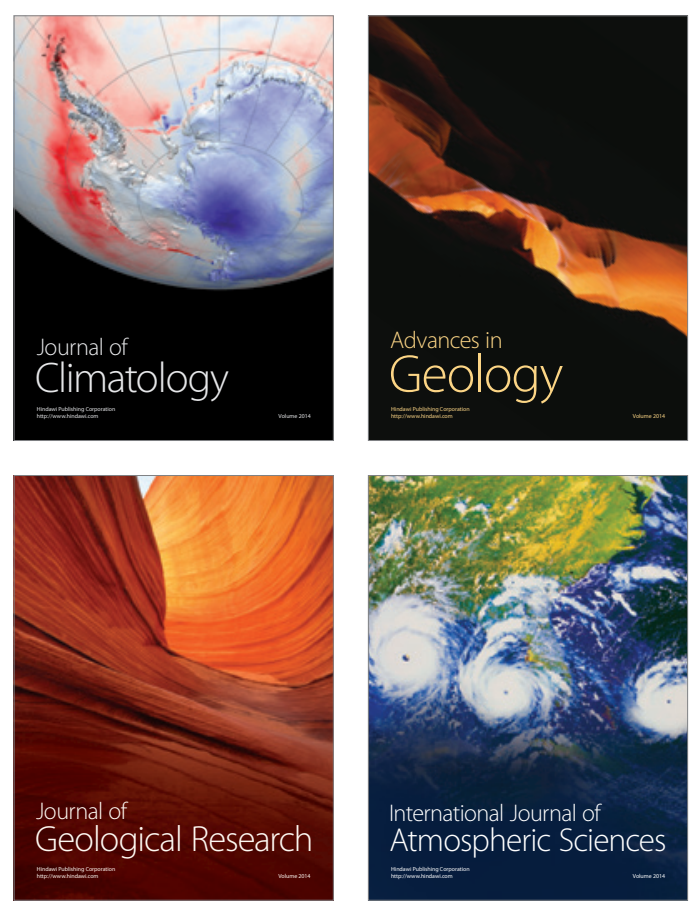
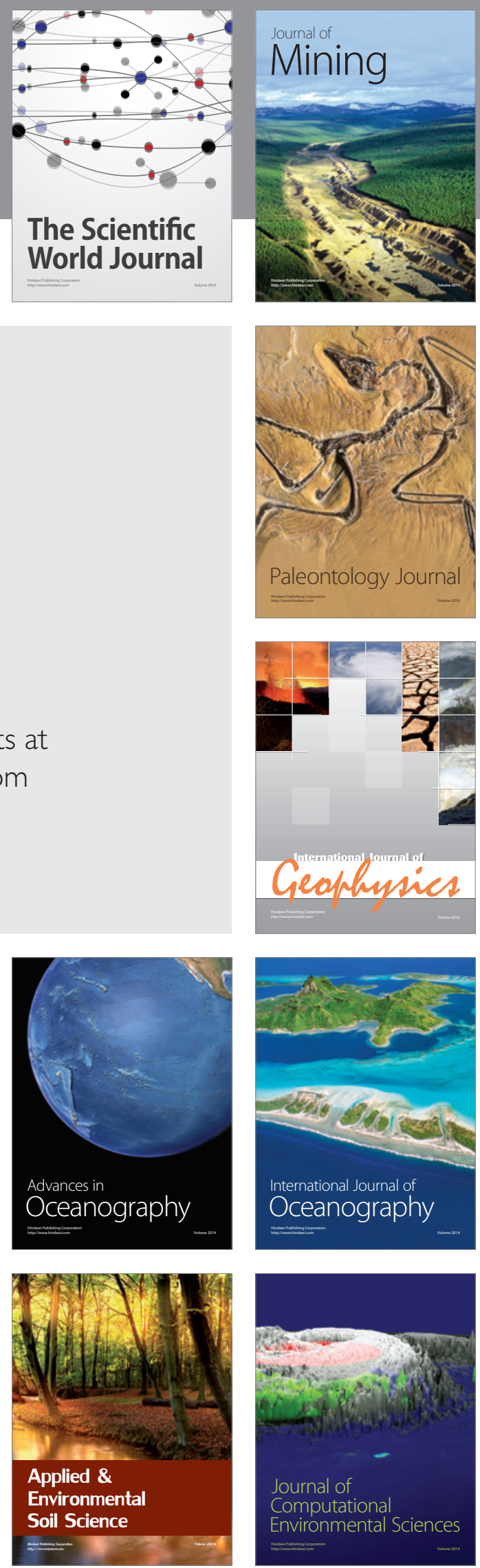